Amgen Inc., Employee of: Employee of Amgen Inc., Vishala Chindalore Grant/ research support from: Nektar Therapeutics for conducted studies, Speakers bureau: > 5 years ago, Stanley Cohen Grant/research support from: Grant and research support from Amgen, AbbVie, Pfizer, Genentech, and Lilly, Consultant of: Consultant for Amgen, AbbVie, Pfizer, Genentech and Lilly, Alan Kivitz Shareholder of: AbbVie, Amgen, Gilead, GSK, Pfizer Inc, Sanofi, Consultant of: AbbVie, Boehringer Ingelheim,,Flexion, Genzyme, Gilead, Janssen, Novartis, Pfizer Inc, Regeneron, Sanofi, SUN Pharma Advanced Research, UCB, Paid instructor for: Celgene, Genzyme, Horizon, Merck, Novartis, Pfizer, Regeneron, Sanofi, Speakers bureau: AbbVie, Celgene, Flexion, Genzyme, Horizon, Merck, Novartis, Pfizer Inc, Regeneron, Sanofi, Maximilian Posch: None declared, Barbara Sullivan Shareholder of: Shareholder of Amgen Inc., Employee of: Former employee of Amgen Inc. Current employee of Ultragenyx, Jane Parnes Shareholder of: Stockholder of Amgen Inc., Employee of: Employee of Amgen Inc.

DOI: 10.1136/annrheumdis-2020-eular.4744

\section{FRI0085 $\quad$ RETENTION RATE OF ADALIMUMAB AND ABP 501 IN THE TREATMENT OF A LARGE COHORT OF PATIENTS WITH INFLAMMATORY ARTHRITIS: A REAL LIFE RETROSPECTIVE ANALYSIS}

A. Becciolini ${ }^{1}$, R. Caccavale ${ }^{2}$, S. Parisi $^{3}$, S. Giordano ${ }^{1}$, E. Bravi ${ }^{4}$, E. DI Donato $^{1}$, F. Lumetti ${ }^{5}$, R. Andracco ${ }^{6}$, M. C. Ditto ${ }^{3}$, D. Santilli ${ }^{1}$, G. Lucchini ${ }^{1}$, A. Volpe $^{7}$, A. Marchetta ${ }^{7}$, F. Mozzani ${ }^{1}$, G. Sandri ${ }^{5}$, F. Girelli ${ }^{8}$, E. Arrigoni ${ }^{4}$, E. Fusaro ${ }^{3}$, M. Paroli ${ }^{2}$, A. Ariani ${ }^{1} .{ }^{1}$ Ospedale Maggiore, Department of Medicine, Internal Medicine and Rheumatology Unit, Parma, Italy; ${ }^{2}$ Sapienza University of Rome, Division of Clinical Immunology and Rheumatology, Department of Biotechnology and Medical Surgical Sciences, Roma, Italy; ${ }^{3}$ Azienda Ospedaliero-Universitaria Città della Salute e della Scienza di Torino, Rheumatology Department, Torino, Italy; ${ }^{4}$ Ospedale "Guglielmo da Saliceto", Department of Medicine, Internal Medicine and Rheumatology Unit, Piacenza, Italy; ${ }^{5}$ University of Modena and Reggio Emilia, Chair of Rheumatology, Modena, Italy; ${ }^{6}$ Hospital Imperia, Department of Internal Medicine, Imperia, Italy; ${ }^{7}$ Ospedale Sacro Cuore Don Calabria, Rheumatology Unit, Negrar, Italy; ${ }^{8}$ Ospedale G.B.Morgagni-L. Pierantoni di Forlì, Internal Medicine Unit, Rheumatology Service, Forli, Italy

Background: The recent introduction of ABP 501, an adalimumab biosimilar, in treatment of rheumatic diseases was supported by a comprehensive comparability exercise with its originator. On the other hand observational studies comparing adalimumab and ABP 501 in inflammatory arthritis are still lacking.

Objectives: To compare the clinical outcomes of the treatment with adalimumab, both originator and biosimilar, in a large cohort of patients affected by autoimmune arthritis in a real life setting.

Methods: We retrospectively analysed the baseline characteristics and the retention rate in a cohort of patients who received at least a course of adalimumab (originator or biosimilar ABP 501) in eight Rheumatology Units from January 2003 to January 2020. We stratified the study population according to biosimilar use. Descriptive data are presented by medians (interquartile range [IQR]) for continuous data or as numbers (percentages) for categorical data. Drug survival distribution curves were computed by the Kaplan-Meier method and compared by a stratified log-rank test. $P$ values $\leq 0.05$ were considered statistically significant.

Results: 764 patients (53.4\% female, median age 55 [44-65] years, median disease duration 60 [25-149] months) treated with adalimumab were included in the analysis. $308(40.3 \%)$ were affect by rheumatoid arthritis, $244(31.9 \%)$ by psoriatic arthritis, and $212(27.7 \%)$ by axial spondylarthritis. $558(73 \%)$ were treated with adalimumab originator and 206 (27\%) with ABP 501. Among the biosimilars $60(29.1 \%)$ patients were naïve to adalimumab treatment. The overall 6-month retentions rate was $93.1 \%$. The 6-month retention rate for adalimumab and ABP 501 were $93.3 \%$ and $91.2 \%$ respectively, without significant differences between the groups $(p=0.541)$. Patients switching from originator to biosimilar showed and overall higher treatment survival when compared to naive (6-month retention rate $95 \%$ vs $90-4 \%$ ), although it was not significant $(p=0.179)$.

Conclusion: In our retrospective study adalimumab originator and its biosimilar ABP 501 showed the same effectiveness. Patients switching from originator to biosimilar showed an higher retention rate when compared to naive.

Disclosure of Interests: Andrea Becciolini Speakers bureau: Sanofi-Genzyme, UCB and AbbVie, rosalba caccavale: None declared, Simone Parisi: None declared, Salvatore Giordano: None declared, Elena Bravi: None declared, eleonora Di Donato: None declared, Federica Lumetti: None declared, Romina Andracco: None declared, Maria Chiara Ditto: None declared, Daniele Santilli: None declared, Gianluca Lucchini: None declared, Alessandro Volpe: None declared, Antonio Marchetta: None declared, Flavio Mozzani: None declared, Gilda Sandri: None declared, Francesco Girelli: None declared, eugenio arrigoni:
None declared, Enrico Fusaro: None declared, marino paroli: None declared, Alarico Ariani: None declared

DOI: 10.1136/annrheumdis-2020-eular.3198

\begin{tabular}{|l|l}
\hline FRI0086 & DISEASE ACTIVITY MEASURES AND OTHER \\
POTENTIAL PREDICTORS OF SUCCESSFUL TNF \\
INHIBITORS TAPERING IN RA PATIENTS
\end{tabular}

$\underline{\text { P. Bogas }}^{1}$, C. Plasencia ${ }^{1}$, F. Guiñazú ${ }^{1}$, M. Novella-Navarro ${ }^{1}$, V. NavarroCompán $^{1}$, K. N. Franco Gomez ${ }^{1}$, I. Monjo ${ }^{1}$, A. Balsa ${ }^{1}{ }^{1}$ La Paz University Hospital, Rheumatology, Madrid, Spain

Background: Biologic therapy (BT) resulted in a substantial improvement of outcomes in Rheumatoid Arthritis (RA). However, it is also associated with higher costs, adverse events and patient's request to dose reduction and drug holidays. Although clinical practice guidelines suggest consider tapering biologics after sustained remission, the optimal approach for de-escalation remains unknown.

Objectives: i) to identify potential features associated with long-term successful TNF inhibitors (TNFi) tapering (Tap) in RA patients (pts), including the possible predictive value of different disease activity measures (DAS28, SDAI, CDAI). ii) to describe long-term outcome in relation to dose reduction of BT.

Methods: Observational prospective study of 91 RA pts who started a firs TNFi between 2000-2014 and in whom tapering (dose down-titrated or interval widen) was applied after achieving sustained remission/Low disease activity. Demographic, clinical and analytical data were collected at biologic initiation. Disease activity was measured using DAS28, SDAI and CDAl at de-escalation start and at $6(6 \mathrm{~m}), 12(12 \mathrm{~m}), 18(18 \mathrm{~m})$ and 24 months $(24 \mathrm{~m})$ follow-up. Tap failure (primary outcome) was defined as reinstatement of full dose, escalation to the previous dose level or discontinuation due to secondary inefficacy. Tap status (Tap failure/success) was also assessed at each studied time point. Mann-Whitney $U$ test and Fisher's exact test were used to test statistical differences. Logistic regression analysis was used to identify predictors of tap failure at 12 and $24 \mathrm{~m}$.

Results: Of the 91 cases included (mean age $53 \pm 12.5$ years, $74 \%$ women), eleven (12\%) experienced Tap failure at the $12 \mathrm{~m}$ mark. At $24 \mathrm{~m}, 18$ pts $(20 \%)$ failed to taper, while $74(80 \%)$ succeeded. At 12 and 24 m no significant differences were found in baseline and pre-Tap characteristics between those who experienced tap failure and those who succeeded (Table 1). In the univariate analysis, at the $12 \mathrm{~m}$ mark, there were no factors related to tapering; however, at $24 \mathrm{~m}$, a longer time from TNFi start to achievement of remission was identified as a predictor of Tap failure $(\mathrm{OR}=1.64, \mathrm{p}=0.02)$; this feature remained associated with failed Tap at $24 \mathrm{~m}$ in the multivariate analysis $(\mathrm{OR}=1.75, \mathrm{p}=0.02)$. Neither of the three disease activity indices measured at Tap initiation predicted long-term tap failure.

Conclusion: In our cohort of RA patients on tapered TNFi, time from TNFi start to achievement of remission seemed to determine successful tapering of biological treatment. However, disease activity scores measured at dose reduction initiation were not predictive of successful de-escalation strategies.

table

\begin{tabular}{|c|c|c|c|c|}
\hline Baseline Characteristics & $\begin{array}{c}\text { Pts who } \\
\text { presented a } \\
\text { tap failure at } \\
24 \mathrm{~m}(\mathrm{n}=18)\end{array}$ & $\begin{array}{c}\text { Pts who } \\
\text { presented a } \\
\text { successful tap } \\
\text { at } 24 m(n=73)\end{array}$ & $\begin{array}{c}\text { Total } \\
\text { population } \\
(\mathrm{n}=91)\end{array}$ & $P$ value \\
\hline Age at TNFi start (years) & $48.4(13.2)$ & $54(12.1)$ & $53(12.5)$ & $P=0.06$ \\
\hline Sex (female) n (\%) & $13(72)$ & $54(74)$ & $67(74)$ & $P=1.00$ \\
\hline Non smokers, n (\%) & $7(41)$ & $41(58)$ & $48(54)$ & $P=0.28$ \\
\hline BMI, m (SD) & $25.3(4.8)$ & $25.5(4.2)$ & 25.5 (4.3) & $P=0.75$ \\
\hline $\mathrm{RF}+, \mathrm{n}(\%)$ & $15(83)$ & $59(81)$ & $74(81)$ & $P=1.00$ \\
\hline CCP, + n (\%) & $13(72)$ & $58(82)$ & $71(80)$ & $\mathrm{P}=0.51$ \\
\hline Monotherapy, n (\%) & $3(17)$ & $8(11)$ & $11(12)$ & $P=0.45$ \\
\hline Disease duration, m (SD) & $8.8(6.6)$ & $10.2(7.1)$ & $9.9(7)$ & $P=0.36$ \\
\hline DAS28 at TNFi start, $m(S D)$ & $4.7(1.3)$ & $4.7(1.1)$ & $4.7(1.2)$ & $\mathrm{P}=0.71$ \\
\hline CDAl at TNFi start, m (SD) & $25.2(23.5)$ & $22.5(12.3)$ & $23.1(15.1)$ & $P=0.64$ \\
\hline SDAl at TNFi start, m (SD) & $23.4(13.7)$ & $22.1(12.4)$ & $22.3(12.6)$ & $\mathrm{P}=0.9$ \\
\hline \multicolumn{5}{|l|}{ Pre-Tap Characteristics: } \\
\hline DAS28 at Tap initiation, $m$ (SD) & $2.3(0.7)$ & $2.4(0.7)$ & $2.4(0.7)$ & $P=0.83$ \\
\hline CDAl at Tap initiation, m (SD) & $3.6(3)$ & $3.5(4.2)$ & $3.5(4)$ & $P=0.47$ \\
\hline SDAI at Tap initiation, $m$ (SD) & $4.4(3)$ & $3.8(4.2)$ & $3.9(3.9)$ & $\mathrm{P}=0.17$ \\
\hline $\begin{array}{l}\text { Time from TNFi start to } \\
\text { achievement of remission }\end{array}$ & $1.9(1.6)$ & $1.1(1)$ & $1.3(1.2)$ & $P=0.08$ \\
\hline Time from achievement of & $2.2(2.5)$ & $2.5(2.6)$ & $2.4(2.5)$ & $P=0.46$ \\
\hline
\end{tabular}

remission to tapering

m, mean; SD, standard deviation

Acknowledgments: We are grateful to all of the rheumatologists and nurses at the Daycare Department for Biologicals and the patients who participated in the registry 
Disclosure of Interests: Patricia Bogas: None declared, Chamaida Plasencia: None declared, Francisco Guiñazú: None declared, Marta Novella-Navarro: None declared, Victoria Navarro-Compán Consultant of: Abbvie, Lilly, Novartis, Pfizer, UCB, Speakers bureau: AbbVie, MSD, Lilly, Novartis, Pfizer, UCB, Karen Nathalie Franco Gomez: None declared, Irene Monjo: None declared, Alejandro Balsa Grant/research support from: BMS, Roche, Consultant of: AbbVie, Gilead, Lilly, Pfizer, UCB, Sanofi, Sandoz, Speakers bureau: AbbVie, Lilly, Sanofi, Novartis, Pfizer, UCB, Roche, Nordic, Sandoz DOI: 10.1136/annrheumdis-2020-eular.5862

\section{FRI0087 DURABILITY OF CERTOLIZUMAB PEGOL IN PATIENTS WITH RHEUMATOID ARTHRITIS OR PSORIASIS OVER THREE YEARS: AN ANALYSIS OF POOLED CLINICAL TRIAL DATA}

V. Bykerk ${ }^{1}$, A. B. Gottlieb ${ }^{2}$, K. Reich ${ }^{3}$, Y. Tanaka ${ }^{4}$, K. Winthrop ${ }^{5}$, C. Popova ${ }^{6}$, N. Tilt ${ }^{7}$, A. Blauvelt ${ }^{8} .{ }^{1}$ Hospital for Special Surgery, New York, United States of America; ${ }^{2}$ Icahn School of Medicine at Mount Sinai, New York, United States of America; ${ }^{3}$ University Medical Center Hamburg-Eppendorf, Hamburg, Germany; ${ }^{4}$ University of Occupational and Environmental Health, Kitakyushu, Japan; ${ }^{5}$ Oregon Health and Science University, Portland, United States of America; ${ }^{6}$ UCB Pharma, Brussels, Belgium; ${ }^{7}$ UCB Pharma, Slough, United Kingdom; ${ }^{8}$ Oregon Medical Research Center, Portland, United States of America

Background: Durability over time varies according to the safety, tolerability and efficacy of a drug. ${ }^{1}$ However, durability may vary between patient (pt) subgroups, ${ }^{1,2}$ and physicians should consider pt characteristics when making treatment decisions. Certolizumab pegol (CZP) is an anti-tumour necrosis factor (anti-TNF) agent approved for the treatment of chronic inflammatory diseases, including rheumatoid arthritis (RA) and plaque psoriasis (PSO). ${ }^{3}$ However, little is known about the impact of pt baseline characteristics on long-term CZP durability.

Objectives: To investigate the durability of CZP and reasons for discontinuation over 3 years (yrs) in subgroups of pts with RA or PSO using pooled clinical trial data.

Methods: 27 RA and 3 PSO clinical trials were pooled for indication-specific analyses. Kaplan-Meier curves were calculated to estimate CZP durability for pt subgroups by age, gender, disease duration, prior anti-TNF use and geographic region. Reasons for CZP discontinuation were investigated.

Results: 6927 RA and 1112 PSO pts were included; mean ages were 53.0 yrs (standard deviation [SD]: 12.2 yrs) and 45.4 (13.0) yrs, respectively. 79.3\% RA pts were female (of all patients, $19.4 \%$ were women of childbearing age [18-<45 yrs; WoCBA]) compared with $33.5 \%$ (15.2\% WoCBA) in PSO. Mean disease durations were 6.4 (6.9) yrs for RA and 18.4 (12.3) yrs for PSO. 18.5\% RA and $13.3 \%$ PSO pts had prior anti-TNF use. Maximum CZP exposure was $~ 8$ yrs for

Table 1. CZP durability at 3 years,[a] by patient subgroup

\begin{tabular}{lll}
\hline \% patients & RA & PSO \\
\hline All & 49.2 & 70.1 \\
Age, yrs & & \\
$\quad$ 18-<45 & 52.1 & 66.3 \\
$45-<65$ & 49.4 & 68.3 \\
$\geq 65$ & 43.3 & 69.4 \\
Gender & & \\
$\quad$ Female & 49.3 & 64.1 \\
Male & 48.2 & 69.2 \\
WoCBA & 51.1 & 62.0 \\
Male aged 18-<45 yrs & 56.5 & 68.3 \\
Prior anti-TNF use & & \\
Yes & 49.3 & 60.1 \\
$\quad$ No & 49.6 & 68.5 \\
Disease duration, yrs & & \\
$\quad<1$ & 43.2 & 39.6 \\
1-<5 & 52.6 & 63.6 \\
5-<10 & 51.4 & 64.4 \\
$\geq 10$ & 48.7 & 69.7 \\
Region & & \\
Asia-Pacific & 58.5 & 78.8 \\
Central Europe & 61.5 & \\
Eastern Europe & 54.2 & 53.9 \\
Latin America & 57.1 & 67.7 \\
N America & 36.6 & \\
W Europe & 33.8 & \\
Rest of the world & 66.3 & \\
\end{tabular}

[a] For PSO, the 3 year analysis was calculated with Week 144 data. CZP: certolizumab pegol; N: North; PSO: psoriasis; RA: rheumatoid arthritis; TNF: tumour necrosis factor; W: Western; yrs: years.
RA and $\sim 3$ yrs for PSO. At $1 \mathrm{yr}, 63.4 \%$ of RA pts remained on CZP vs $80.3 \%$ PSO pts, decreasing to $49.2 \%$ RA pts and $70.1 \%$ PSO pts at 3 yrs (Table 1). Reasons for discontinuation, at any time during the trials, included lack of efficacy (RA $13.5 \%$; PSO 1.8\%), adverse events (RA 11.9\%; PSO $8.1 \%$ ), consent withdrawn (RA 6.7\%; PSO 6.7\%), lost to follow-up (RA 1.8\%; PSO 4.3\%), protocol violation (RA 1.7\%; PSO 0.3\%) and other (RA 9.2\%; PSO 8.7\%). In RA pts, CZP durability was lower in the elderly and in pts with disease duration $<1$ yr. In PSO, durability was lower in pts with disease duration $<1$ yr or prior anti-TNF use. Durability was lower in WoCBA pts than male pts aged $18-<45$ yrs for both indications. CZP durability was lower in Western Europe and North America compared to other regions.

Conclusion: Overall, CZP durability was similar to that reported for other antiTNFs with some differences between indication and subgroups. ${ }^{1}$ Factors influencing durability included age, disease duration and geographic region. Gender differences were observed in the 18-45 yrs age group, however, both male and female CZP durability was higher than in older RA pts.

References:

[1] Neovius M. Ann Rheum Dis 2015;74:354-60; 2. Lie E. Ann Rheum Dis 2015;74:970-8; 3. EMA. CIMZIA SmPC 2019. Available at: https://www.ema. europa.eu [Last accessed 09/01/20].

Acknowledgments: This study was funded by UCB Pharma. Editorial services were provided by Costello Medical.

Disclosure of Interests: Vivian Bykerk: None declared, Alice B Gottlieb Grant/ research support from:: Research grants, consultation fees, or speaker honoraria for lectures from: Pfizer, AbbVie, BMS, Lilly, MSD, Novartis, Roche, Sanofi, Sandoz, Nordic, Celltrion and UCB., Consultant of:: Research grants, consultation fees, or speaker honoraria for lectures from: Pfizer, AbbVie, BMS, Lilly, MSD, Novartis, Roche, Sanofi, Sandoz, Nordic, Celltrion and UCB., Speakers bureau:: Research grants, consultation fees, or speaker honoraria for lectures from: Pfizer, AbbVie, BMS, Lilly, MSD, Novartis, Roche, Sanofi, Sandoz, Nor dic, Celltrion and UCB., Kristian Reich Grant/research support from: Affibody Almirall; Amgen; Biogen; Boehringer Ingelheim; Celgene; Centocor; Covagen; Eli Lilly; Forward Pharma; Fresenius Medical Care; GlaxoSmithKline; Janssen; Kyowa Kirin; LEO Pharma; Medac; Merck; Novartis; Miltenyi Biotec; Ocean Pharma; Pfizer; Regeneron; Samsung Bioepis; Sanofi Genzyme; Takeda; UCB; Valeant and Xenoport., Consultant of: Affibody; Almirall; Amgen; Biogen; Boehringer Ingelheim; Celgene; Centocor; Covagen; Eli Lilly; Forward Pharma; Fresenius Medical Care; GlaxoSmithKline; Janssen; Kyowa Kirin; LEO Pharma; Medac; Merck; Novartis; Miltenyi Biotec; Ocean Pharma; Pfizer; Regeneron; Samsung Bioepis; Sanofi Genzyme; Takeda; UCB; Valeant and Xenoport., Speakers bureau: Affibody; Almirall; Amgen; Biogen; Boehringer Ingelheim; Celgene; Centocor; Covagen; Eli Lilly; Forward Pharma; Fresenius Medical Care; GlaxoSmithKline; Janssen; Kyowa Kirin; LEO Pharma; Medac; Merck; Novartis; Miltenyi Biotec; Ocean Pharma; Pfizer; Regeneron; Samsung Bioepis; Sanofi Genzyme; Takeda; UCB; Valeant and Xenoport., Yoshiya Tanaka Grant/research support from: Asahi-kasei, Astellas, Mitsubishi-Tanabe, Chugai, Takeda, Sanofi, Bristol-Myers, UCB, Daiichi-Sankyo, Eisai, Pfizer, and Ono, Consultant of: Abbvie, Astellas, Bristol-Myers Squibb, Eli Lilly, Pfizer, Speakers bureau: Daiichi-Sankyo, Astellas, Chugai, Eli Lilly, Pfizer, AbbVie, YL Biologics, Bristol-Myers, Takeda, Mitsubishi-Tanabe, Novartis, Eisai, Janssen, Sanofi, UCB, and Teijin, Kevin Winthrop Grant/research support from: Bristol-Myers Squibb, Consultant of: AbbVie, Bristol-Myers Squibb, Eli Lilly, Galapagos, Gilead, GSK, Pfizer Inc, Roche, UCB, Christina Popova Employee of: UCB Pharma, Nicola Tilt Employee of: UCB Pharma, Andrew Blauvelt Consultant of: AbbVie, Aclaris, Almirall, Arena Athenex, Boehringer Ingelheim, Bristol-Myers Squibb, Dermavant, Dermira, Eli Lilly, FLX Bio, Forte, Galderma, Janssen, Leo, Novartis, Ortho, Pfizer, Regeneron, Sandoz, Sanofi Genzyme, Sun Pharma, and UCB Pharma, Speakers bureau: AbbVie

DOI: 10.1136/annrheumdis-2020-eular.1682

\section{FRI0088}

\section{CHANGE IN SERUM BILIRUBIN SUGGESTS} TREATMENT RESPONSE IN RHEUMATOID ARTHRITIS PATIENTS TREATED WITH MOLECULAR-TARGETED AGENTS

S. J. Choi ${ }^{1}$, S. H. Nam ${ }^{1}$, J. S. Lee', W. J. Seo ${ }^{2}$, J. S. Oh ${ }^{3}$, S. $\mathrm{Hong}^{1}$, C. K. Lee ${ }^{1}$, B. Yoo ${ }^{1}$, Y. G. Kim ${ }^{1} .{ }^{1}$ University of Ulsan College of Medicine, Asan Medical Center, Division of Rheumatology, Department of Internal Medicine, Seoul, Korea, Rep. of (South Korea); ${ }^{2}$ Seoul Veterans Hospital, Division of Rheumatology, Department of Internal Medicine, Seoul, Korea, Rep. of (South Korea): ${ }^{3}$ Asan Medical Center, Department of Biomedical Informatics, Seoul, Korea, Rep. of (South Korea)

Background: Bilirubin is an antioxidant with anti-inflammatory properties. In previous reports, serum bilirubin levels were correlated with disease activity of autoimmune diseases including rheumatoid arthritis (RA). Various molecular-targeted 